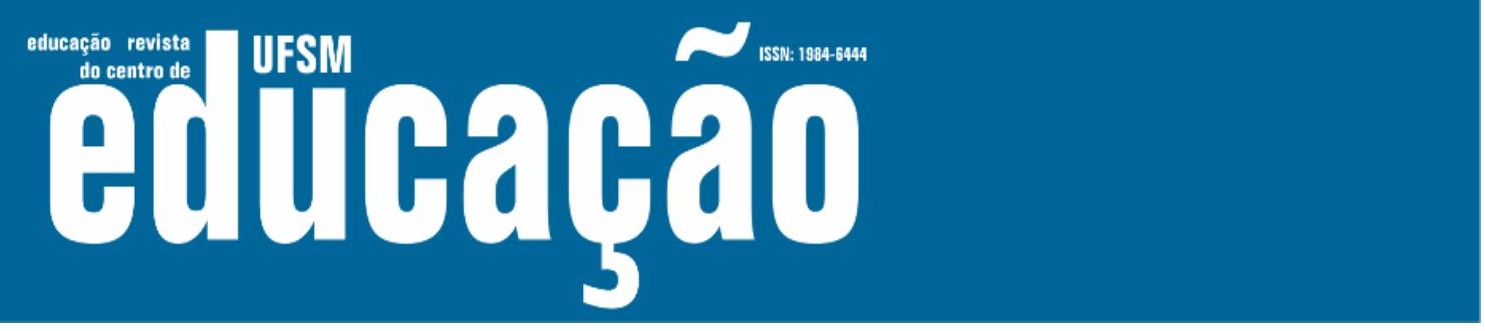

ISSN: 1984-6444 | http://dx.doi.org/10.5902/1984644438298

\title{
Atratividade no ingresso e permanência na carreira docente em redes municipais de educação'
}

Attractiveness to entering and staying in teaching carrier in municipal education networks

Michelle Fernandes Lima

Professora doutora na Universidade Estadual do Centro Oeste, Campus Irati. Irati, Paraná, Brasil. mfernandeslima@yahoo.com.br - http://orcid.org/0000-0003-0896-4747

Gisele Masson

Professora doutora na Universidade Estadual de Ponta Grossa. Ponta Grossa, Paraná, Brasil. gimasson@uol.com.br - https://orcid.org/0000-0002-9799-5950

Recebido em 26 de maio de 2019

Aprovado em 04 de fevereiro de 2019

Publicado em 10 de agosto de 2020

\section{RESUMO}

Este artigo é parte integrante de pesquisa de pós-doutoramento realizada no Programa de Pós-Graduação em Educação da Universidade Estadual de Ponta Grossa e vinculada ao Grupo de Pesquisa Estado, Políticas e Gestão da Educação (UNICENTRO/PR) e ao Grupo Capital, Trabalho, Estado e Educação: Políticas Educacionais e Formação de Professores (UEPG/PR). A referida pesquisa teve como objetivo central analisar dados sobre os Planos de Carreira dos docentes das 35 redes municipais de educação das mesorregiões Sudeste e Centro-Oriental do Paraná, para verificar a atratividade no ingresso e permanência na carreira docente. Planos de carreira e tabelas salariais atualizadas foram utilizados como fontes de estudo. Pelos dados levantados, este texto observa que a valorização do professor, de acordo com a titulação desde o início da carreira, não ocorre na quase totalidade das redes, e diversos desafios ainda precisam ser superados para a garantia da valorização docente.

Palavras-chave: Carreira docente; Planos de carreira dos professores; Atratividade.

\section{ABSTRACT}

This issue integrates a post-doctoral research carried out in the Graduation Program in Education of the State University of Ponta Grossa and linked to the Research Group State, Policies and Education Management (UNICENTRO/PR). The research mentioned had as central aim at analyzing data on the Career Plans of 35 municipal education networks of Southwest and central-oriental mesoregions of Paraná in order to verify attractiveness to entering and staying in teaching carrier. Career plans and up-to-date wage tables were used as study sources. According to data surveyed, this 


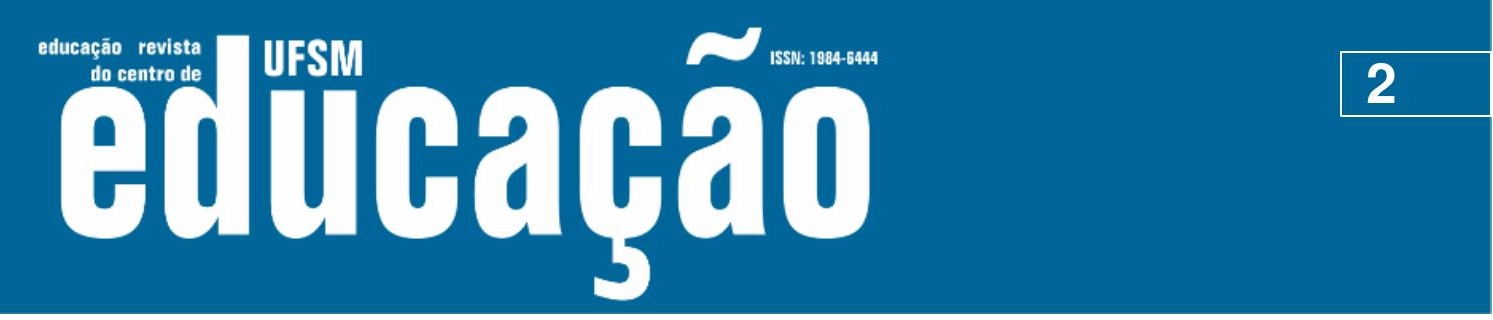

ISSN: 1984-6444 | http://dx.doi.org/10.5902/1984644438298

text observes that teaching appreciation, according to their degree since starting the career does not occur in almost all the networks, and several challenges still need to be overcome to ensure teaching appreciation.

Keywords: Teaching career; Teacher Career Plans; attractiveness.

\section{Introdução}

O objetivo deste artigo é analisar os planos de carreira dos professores das redes municipais das Regiões Sudeste e Centro-Oriental do Paraná, especificamente a atratividade no ingresso e na permanência dos docentes nos $35^{2}$ municípios contemplados na pesquisa. A valorização docente é um tema complexo e abrangente, e muitos elementos podem ser investigados, como condições de trabalho, remuneração, e formação inicial e continuada.

A problemática da investigação centrou-se na seguinte questão: os planos de carreira dos professores da Educação Básica das redes municipais das Regiões Sudeste e Centro Oriental do Paraná estão organizados para garantir a atratividade e a permanência na carreira docente?

Deste modo, realizamos levantamento dos planos de carreira dos professores, o que exigiu maior tempo de pesquisa e a contribuição de estudantes e professores dos dois grupos de pesquisa envolvidos na investigação, pois houve dificuldades para acessar a legislação dos municípios pela não publicação de informações nos sites das instituições. Os dados referentes aos planos foram obtidos nos sites das prefeituras e câmaras municipais, assim como do portal da transparência, dos editais de concursos e de contatos via e-mail e telefone com a seção de recursos humanos das prefeituras.

Como nossa questão central foi verificar se a forma como esses planos estão organizados garantem a atratividade no ingresso e na permanência na carreira docente, foi fundamental apontar o que estamos considerando como requisitos essenciais para a atratividade. Partimos do estudo realizado por Masson (2017), que apresentou parâmetros iniciais para a análise a respeito da atratividade nos planos de carreira dos 35 municípios das Regiões Sudeste e Centro-Oriental do Paraná.

Masson (2017), a partir de pesquisa documental, dados estatísticos e amplo estudo sobre a valorização docente, indicou sete requisitos essenciais que podem 


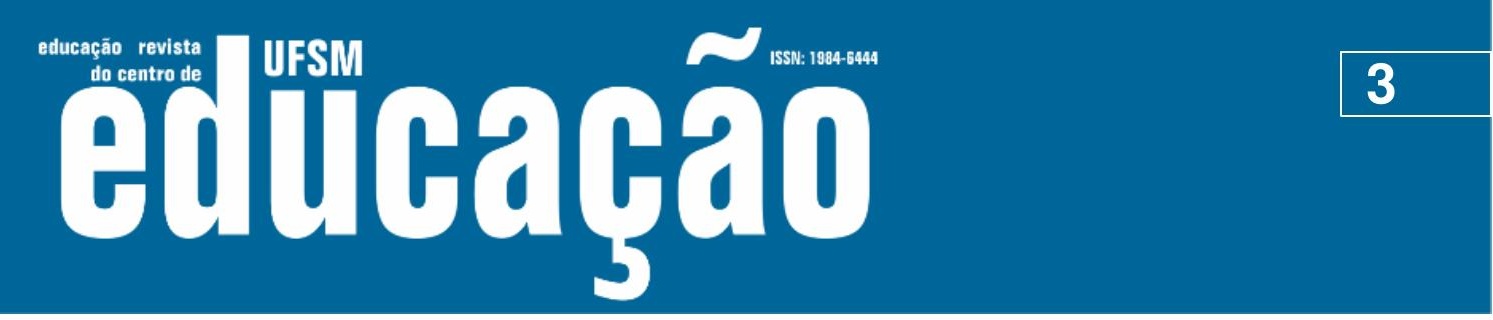

ISSN: 1984-6444 | http://dx.doi.org/10.5902/1984644438298

garantir a atratividade: 1. Remuneração proporcional à formação com equiparação às demais profissões de formação equivalente; 2 . Ascensão na carreira de acordo com o tempo de serviço e titulação; 3. Alcance do topo da carreira como uma possibilidade para todos e não restrito à minoria; 4. Progressão horizontal com interstícios não muitos longos; 5. Valorização do professor de acordo com sua titulação desde o início da carreira; 6. Dispersão salarial; 7. Consideração do vencimento em relação ao custo de vida regional.

Estes requisitos nortearam nossa análise sobre a atratividade nos planos de carreira; no entanto, priorizamos os cinco primeiros, pois eles poderiam ser mais bem explorados nos dados coletados acerca dos planos dos 35 municípios. O estudo realizado pretende contribuir com o debate sobre a atratividade dos planos em duas regiões do estado do Paraná (PR). Sendo assim, no primeiro momento, apresentamos dados gerais sobre os planos de carreira dos professores nas regiões investigadas. $\mathrm{Na}$ sequência, destacamos as formas de ingresso na carreira e a formação mínima exigida, a jornada de trabalho e sua composição, a estrutura e a movimentação na carreira. Por último, apresentamos dados acerca do vencimento inicial e final dos professores das redes municipais da Região Sudeste e Centro-Oriental do Paraná.

\section{Plano de carreira e vencimento dos professores das redes municipais das regiões Sudeste e Centro-Oriental do Paraná}

A Região Sudeste do Paraná é formada por 21 municípios, dividida em quatro microrregiões, e a Região Centro-Oriental é formada por 14 municípios, dividida em três microrregiões, conforme informações apresentadas no quadro a seguir.

Quadro 1 - Municípios das Regiões Sudeste e Centro Oriental do Paraná - 2016

\begin{tabular}{|l|l|}
\hline \multicolumn{1}{|c|}{ REGIÃO SUDESTE } & \multicolumn{1}{|c|}{ REGIÃO CENTRO-ORIENTAL } \\
\hline Antônio Olinto; Bituruna; Cruz Machado; & Arapoti; Carambeí; Castro; Imbaú; Jaguariaíva; \\
Fernandes Pinheiro; General Carneiro; & Ortigueira; Palmeira; Piraí do Sul; Ponta \\
Guamiranga; Imbituva; Ipiranga; Irati; Ivaí; & Grossa; Reserva; Sengés; Telêmaco Borba; \\
Mallet; Paula Freitas; Paulo Frontin; Porto & Tibagi; Ventania. \\
Vitória; Prudentópolis; Rebouças; Rio Azul; São & \\
João do Triunfo; São Mateus do Sul; Teixeira & \\
Soares; União da Vitória. & \\
\hline
\end{tabular}

Fonte: Elaborado pelas autoras com dados de IPARDES (2016). 


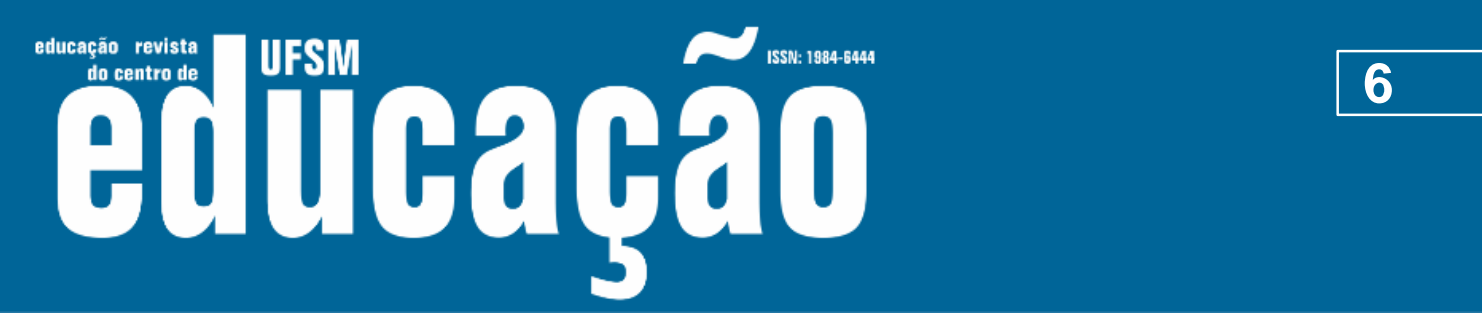

ISSN: 1984-6444 | http://dx.doi.org/10.5902/1984644438298

Continuação Quadro 3 - Leis de Planos de Carreira e Remuneração do Magistério das Mesorregiões Sudeste e Centro-Oriental do Paraná: fontes de acesso aos planos e dificuldade e/ou facilidade de acesso

\begin{tabular}{|c|c|c|c|}
\hline Paulo Frontin & Lei $n^{\circ} 366 / 2009$ & $\begin{array}{l}\text { Contato Recursos } \\
\text { Humanos }\end{array}$ & Difícil \\
\hline Porto Vitória & Lei ํo 675/2003 & Prefeitura Municipal & Difícil \\
\hline Prudentópolis & Lei $n^{0}$ 1829/2011 & Prefeitura Municipal & Fácil \\
\hline Rebouças & Lei oㅜ 1191/2008 & Leis Municipais & Fácil \\
\hline Rio Azul & Lei ํo 756/2014 & $\begin{array}{l}\text { Contato Secretaria de } \\
\text { Educação }\end{array}$ & Difícil \\
\hline $\begin{array}{l}\text { São João do } \\
\text { Triunfo }\end{array}$ & Lei no $860 / 2003$ & $\begin{array}{l}\text { Contato Recursos } \\
\text { Humanos }\end{array}$ & Difícil \\
\hline $\begin{array}{l}\text { São Mateus do } \\
\text { Sul }\end{array}$ & Lei $n^{\circ}$ 2000/2010 & Prefeitura Municipal & Difícil \\
\hline Teixeira Soares & Lei no 1709/ 2015. & $\begin{array}{l}\text { Contato Secretaria de } \\
\text { Educação }\end{array}$ & Difícil \\
\hline União da Vitória & Lei ํㅜ 3332/2005 & Câmara Municipal & Fácil \\
\hline \multicolumn{4}{|l|}{$\begin{array}{l}\text { REGIÃO CENTRO- } \\
\text { ORIENTAL }\end{array}$} \\
\hline Arapoti & Lei no $703 / 2003$ & Câmara Municipal & Difícil \\
\hline Carambeí & Lei $n^{\circ}$ 924/2012 & Leis Municipais & Fácil \\
\hline Castro & Lei $n^{\circ} 183 / 2007$ & Leis Municipais & Fácil \\
\hline Imbaú & Lei no $407 / 2011$ & Controle Municipal & Difícil \\
\hline Jaguariaíva & Lei no 1589/2004 & Câmara Municipal & Difícil \\
\hline Ortigueira & Lei ํo 137/2011 & $\begin{array}{l}\text { Portal da } \\
\text { Transparência/Secretaria } \\
\text { de Educação }\end{array}$ & Fácil \\
\hline Palmeira & Lei $n^{0} 4133 / 2016$ & Leis Municipais & Fácil \\
\hline Piraí do sul & Lei $n^{0} 1830 / 2011$ & Prefeitura Municipal & Fácil \\
\hline Ponta Grossa & Lei $n^{0}=12269 / 2015$ & Leis Municipais & Fácil \\
\hline Reserva & Lei $n^{0}=591 / 2014$ & Prefeitura Municipal & Fácil \\
\hline Sengés & Lei $n^{\circ} 058 / 2005$ & Não disponível & Não disponível \\
\hline Telêmaco Borba & Lei $n^{0}=1866 / 2012$ & Prefeitura Municipal & Fácil \\
\hline Tibagi & Lei no $2574 / 2015$ & Diário Oficial & Difícil \\
\hline Ventania & Lei $n^{\circ}=709 / 2016$ & Câmara Municipal & Fácil \\
\hline
\end{tabular}

Fonte: Sites das prefeituras, Câmara Municipal, Diário Oficial, Leis Municipais, Portal da Transparência, contato via e-mail e telefone com a seção de Recursos Humanos das prefeituras (2017), elaborado pelas autoras.

Para caracterizar a carreira dos professores das redes municipais pesquisadas, elencamos alguns itens que consideramos mais relevantes a partir de leituras e reflexões para o conhecimento geral da estrutura e organização da carreira. São eles: forma de ingresso na carreira e formação mínima exigida; jornada de trabalho e respectiva composição; estrutura e movimentação na carreira (promoções, 


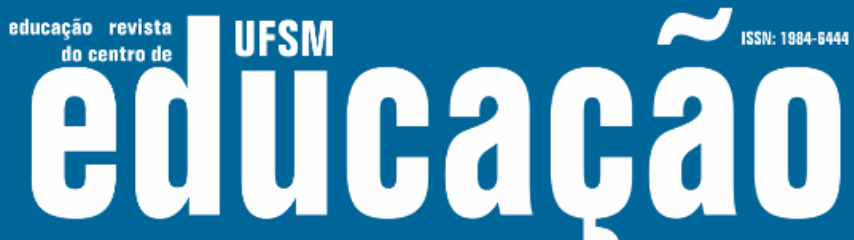

ISSN: 1984-6444 | http://dx.doi.org/10.5902/1984644438298

cargo de professor foram os seguintes: baixa remuneração associada às péssimas condições de trabalho; baixa remuneração e oportunidade de emprego mais rentável; baixa remuneração associada à necessidade de tempo livre para concluir a pósgraduação; baixa remuneração vinculada à falta de perspectiva de crescimento profissional; falta de perspectiva quanto às mudanças na rede de ensino; nascimento de filhos; baixa remuneração mais o desencanto com a profissão; baixa remuneração associada à mudança de cidade; mudança de cidade; falta de condições dignas de trabalho; insatisfação com a estrutura do sistema educacional; problemas de saúde; e trabalhar em negócio próprio.

Normalmente há mais de um motivo para a desistência da profissão, mas, dentre as razões indicadas pelos professores que participaram da pesquisa de Lapo e Bueno (2003), nota-se um peso consideravelmente maior para a baixa remuneração.

A tabela seguinte apresenta os vencimentos médios, inicial e final, de acordo com a titulação e tempo de serviço.

Tabela 2 - Vencimentos médios por níveis de formação e ascensões para as Mesorregiões Sudeste e Centro-Oriental do Paraná, jornada de 20 horas - 2017

\begin{tabular}{l|l|llll}
\hline & Mesorregião & Médio & Superior & Especialização & Mestrado e Doutorado \\
\hline \multirow{2}{*}{ Inicial } & Centro-Oriental & $1.160,78$ & $1.369,84$ & $1.501,71$ & $1.655,79$ \\
& Sudeste & $1.205,05$ & $1.520,85$ & $1.702,63$ & $1.768,21$ \\
\hline \multirow{2}{*}{ Final } & Centro-Oriental & $1.916,83$ & $2.312,06$ & $2.554,15$ & $2.819,96$ \\
& Sudeste & $1.648,05$ & $2.122,83$ & $2.388,13$ & $2.475,88$ \\
\hline
\end{tabular}

Fonte: Dados das tabelas salariais dos municípios pesquisados, elaborada pelas autoras.

Considerando que, para o início de carreira ocorrem vencimentos ligeiramente superiores da mesorregião Sudeste em relação à Centro-Oriental, e o contrário ocorrendo para o final de carreira, procedemos aos cálculos de diferenças percentuais de vencimentos entre as mesorregiões, que são apresentados na Tabela 3. Dado que ocorre uma inversão de superioridade de remuneração entre as mesorregiões para o início e o final de carreira, procedemos ao cálculo do tempo de carreira para que ocorra a igualdade entre os vencimentos das duas mesorregiões. Os tempos foram 


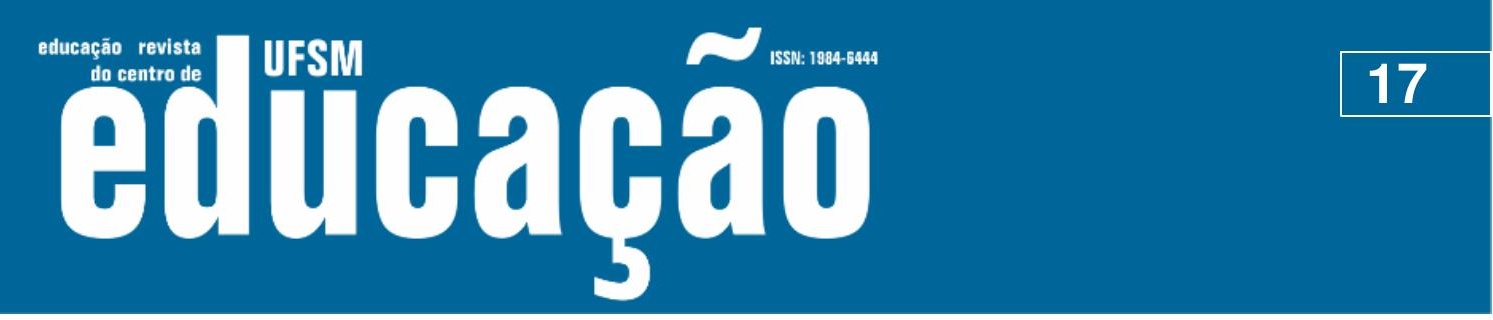

ISSN: 1984-6444 | http://dx.doi.org/10.5902/1984644438298

de cursar mestrado ou doutorado, e não há outras formas previstas de ascensão aos últimos níveis, além da titulação, o que pode levar o professor a estacionar na carreira muito precocemente. Sobre a progressão horizontal com interstícios não muitos longos, identificamos que os planos contemplam períodos de 2 e 3 anos, em alguns casos é possível avançar duas referências.

Pelos dados levantados, observamos que a valorização do professor, de acordo com a titulação desde o início da carreira, não ocorre na quase totalidade das redes. Como o Ensino Médio, modalidade normal, é o critério mínimo para ingresso, os professores com nível superior sofrem prejuízos e perdas salarias, pois muitos necessitam cumprir o período de estágio probatório. No entanto, já existe jurisprudência para o enquadramento do professor efetivo, ainda não estável, no nível e/ou classe conforme a sua titulação, mas a garantia desse direito pela via judicial pode trazer inconvenientes aos professores, como gastos financeiros e constrangimentos que poderiam ser evitados.

\section{Referências}

ABREU, Diana Cristina de. Ingresso e evolução na carreira docente nas redes estadual do Paraná e municipal de Curitiba. In: CAMARGO, Rubens Barbosa de; JACOMINI, Marcia Aparecida. Valorização docente na educação básica: análise dos planos de carreira. São Paulo: Xamã, 2016.

ANTONIO OLINTO. Lei $n^{\circ}$ 484/1998. Estatuto do Magistério Público de Antonio Olinto (PR). Câmara Municipal de Antonio Olinto: Antonio Olinto, 2006.

ARAPOTI. Lei n 703/2003. Plano de Empregos, Carreira e remuneração do Magistério Público Municipal de Arapoti (PR). Câmara Municipal de Arapoti: Arapoti, 2003.

ARAPOTI. Prefeitura Municipal de Arapoti. Concurso Público $\mathbf{n}^{\circ}$ 001/2014. Edital $n^{\circ}$ $001 / 2014$.

AZEVEDO, Francielly. 93 municípios do Paraná não seguem o piso salarial nacional para os professores. Publicado: 19, junho 2017 às 18:12. Disponível em: http://paranaportal.uol.com.br/cidades/93-municipios-do-parana-nao-seguem-o-pisosalarial-nacional-para-os-professores/. Acesso em: 01 jul. 2017. 


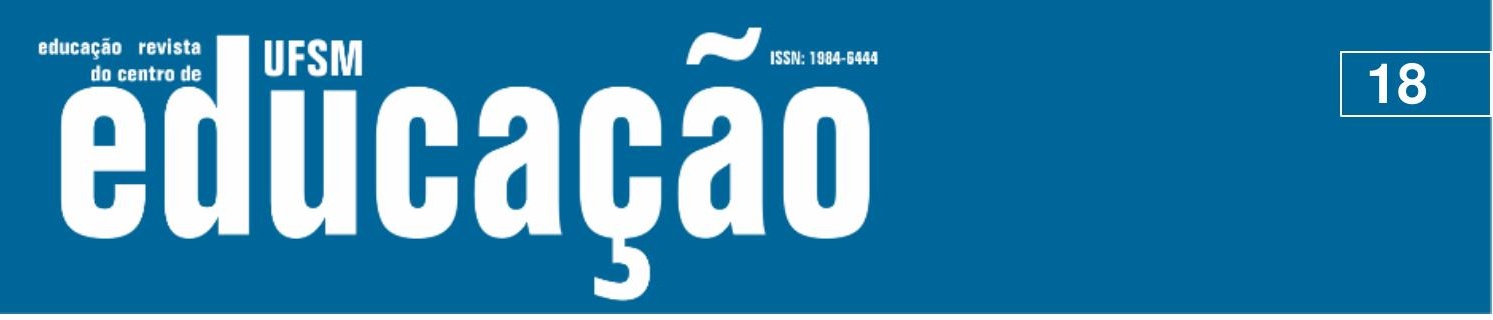

ISSN: 1984-6444 | http://dx.doi.org/10.5902/1984644438298

BITURUNA. Lei n 847/2002. Plano de Empregos, Carreira e remuneração do Magistério Público Municipal de Bituruna (PR). Câmara Municipal de Bituruna: Bituruna, 2002.

BITURUNA. Prefeitura Municipal de Bituruna. Concurso Público n 001/2015. Edital $n^{\circ} 001 / 2015$.

BRASIL. Emenda Constitucional $N^{\circ} 19$ de 04 de junho de 1998. Disponível em: http://www.planalto.gov.br/ccivil_03/Constituicao/Emendas/Emc/emc19.htm. Acesso: 15 maio, 2017.

BRASIL. Emenda Constitucional N 53 de 19 de dezembro de 2006. Disponível em: http://www.planalto.gov.br/ccivil_03/constituicao/emendas/emc/emc53.htm. Acesso em: 12 maio, 2017.

BRASIL. INEP/MEC. Sinopses Estatísticas da Educação Básica 2016. Disponível em: http://portal.inep.gov.br/web/guest/sinopses-estatisticas-da-educacao-basica. Acesso em: 10 jun. 2017.

BRASIL. Lei de Diretrizes e Bases da Educação Nacional. Lei número 9394, de 20 de dezembro de 1996.1 Disponível em: http://www2.senado.leg.br/bdsf/bitstream/handle/id/529732/lei_de_diretrizes_e_base s_1ed.pdf. Acesso em: 01 jun. 2017.

BRASIL. Lei no 11.738 , de 16 de julho de 2008. Regulamenta a alínea "e" do Inciso III do caput do art. 60 do Ato das Disposições Constitucionais Transitórias, para instituir o piso salarial profissional nacional para os profissionais do magistério público da educação básica. Diário Oficial da União, Brasília, 2008. Disponível em: Disponível em: http://www.planalto.gov.br/ccivil_03/_ato2007-2010/2008/lei/l11738.htm. Acesso em: 3 abr. 2016.

BRASIL. Constituição da República Federativa do Brasil de 1988. Brasília, 1988. Disponível em: Disponível em: http://www.planalto.gov.br/ccivil_03/constituicao/constituicaocompilado. Acesso em: 7 dez. 2015.

CARAMBEÍ. Lei no 924/2012. Plano de Empregos, Carreira e remuneração do Magistério Público Municipal de Carambeí (PR). Prefeitura Municipal de Carambeí. Carambeí, 2012.

CARAMBEÍ. Prefeitura Municipal de Carambeí. Concurso Público n 59/2016. Edital $n^{\circ} 59 / 2016$.

CASTRO. Lei n 183/2007. Plano de Empregos, Carreira e remuneração do Magistério Público Municipal de Castro (PR). Câmara Municipal de Castro: Castro, 2007. 


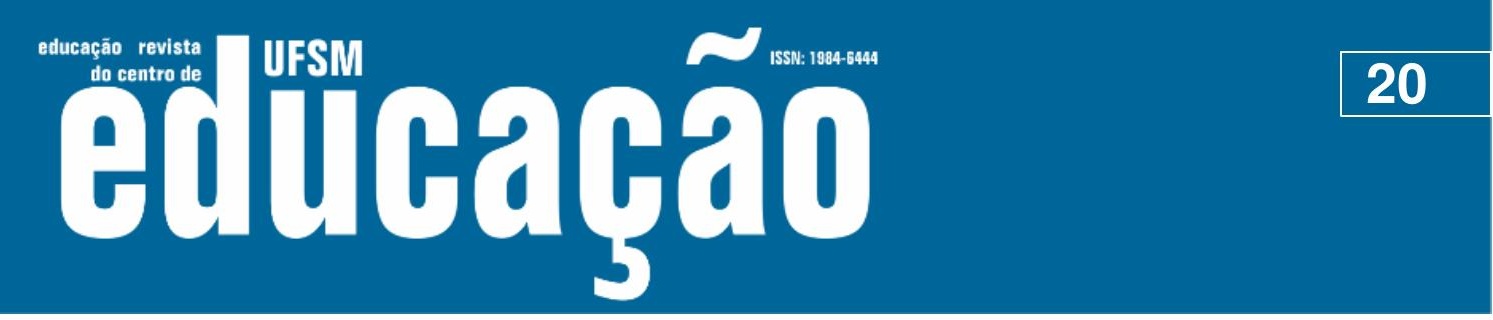

ISSN: 1984-6444 | http://dx.doi.org/10.5902/1984644438298

IMBAÚ. Prefeitura Municipal de Imbaú. Teste Seletivo para provimento de vagas temporárias na Prefeitura Municipal de Imbaú - Paraná. Edital 062/2017

IMBITUVA. Lei $n^{\circ}$ 1550/2014. Plano de Empregos, Carreira e remuneração do Magistério Público Municipal de Imbituva (PR). Câmara Municipal de Imbituva: Imbituva, 2014.

IMBITUVA. Prefeitura Municipal de Imbituva. Concurso Público n 001/2012. Edital $n^{\circ} 001 / 2012$.

IPARDES. Base de Dados do Estado-BDEweb. Disponível em: http://www.ipardes.pr.gov.br/imp/index.php. Acesso em: 01 jun. 2017.

IPARDES. Perfil avançado dos municípios. Disponível em: http://www.ipardes.gov.br/index.php?pg_conteudo=1\&cod_conteudo=29. Acesso em: 13 set. 2017.

IPIRANGA. Lei $\mathbf{n}^{\circ}$ 27/2012. Dispõe sobre a reformulação do Estatuto do Magistério e do Plano de Carreira e Remuneração e dá outras providências. Câmara Municipal de Ipiranga, 2012.

IPIRANGA. Prefeitura Municipal de Ipiranga. Concurso Público n 001/2016. Edital $n^{\circ} 001 / 2016$.

IRATI. Lei n²473/2006. Plano de Cargos, Carreira e Remuneração do Magistério Público Municipal de Irati (PR). Câmara Municipal de Irati: Irati, 2006.

IRATI. Lei n²806/2008. Súmula: Dá nova denominação ao cargo de Monitor de Creche, inclui seus ocupantes no Plano de Carreira do Magistério Municipal e dá outras providências. Câmara Municipal de Irati: Irati, 2008.

IVAÍ. Lei n 914/2009. Plano de Cargos, Carreira e Remuneração do Magistério Público Municipal de Ivaí (PR). Câmara Municipal de Ivaí: Ivaí, 2009.

IVAÍ. Prefeitura Municipal de Ivaí. Concurso Público n 004/2014. Edital n 004/2014. JAGUARIAÍVA. Lei n 1589/2004. Plano de Empregos, Carreira e remuneração do Magistério Público Municipal de Jaguariaíva (PR). Câmara Municipal de Jaguariaíva: Jaguariaíva, 2004.

JAGUARIAÍVA. Prefeitura Municipal de Jaguariaíva. Concurso Público n 001/2016. Edital $n^{\circ} 001 / 2016$.

LAPO, Flavinês Rebolo; BUENO, Belmira Oliveira. Professores, desencanto com a profissão e abandono do magistério. Cadernos de Pesquisa, São Paulo, n. 118, p. 65-88, mar. 2003. 


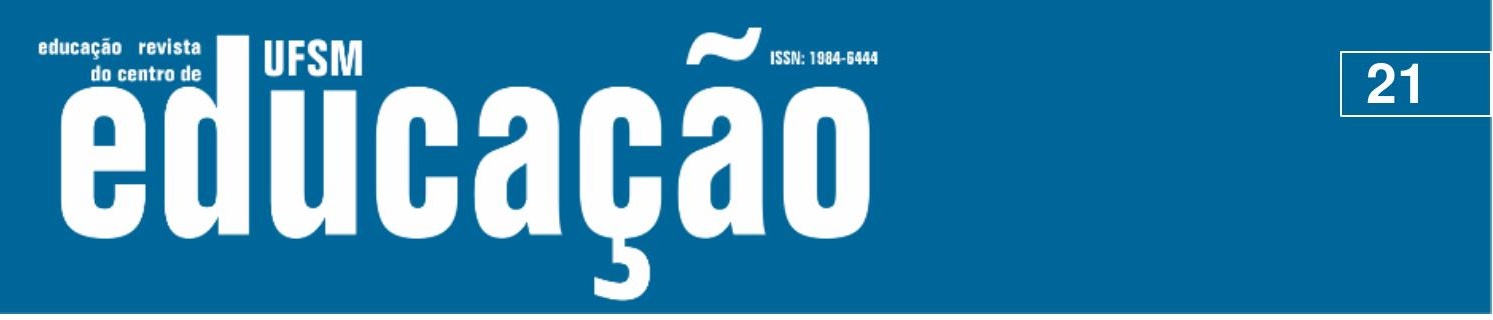

ISSN: 1984-6444 | http://dx.doi.org/10.5902/1984644438298

MALLET. Lei $n^{\circ}$ 1236/2015. Plano de Empregos, Carreira e remuneração do Magistério Público Municipal de Mallet (PR). Câmara Municipal de Mallet: Mallet, 2015.

MALLET. Prefeitura Municipal de Mallet. Concurso Público $\mathbf{n}^{\circ}$ 001/2014. Edital $n^{\circ}$ $001 / 2014$.

MASSON, Gisele. Requisitos essenciais para a atratividade e a permanência na carreira docente. Educ. Soc. [online]. In press. Maio 25, 2017. ISSN 0101-7330. http://dx.doi.org/10.1590/es0101-73302017169078.

MORENO, Ana Carolina. 99\% dos professores brasileiros ganham em média menos de $R \$ 3,5$ mil, diz estudo. G1. 22/06/2017. Disponível em: https://g1.globo.com/educacao/noticia/99-dos-professores-brasileiros-ganhammenos-de-r-35-mil-diz-estudo.ghtml. Acesso em: 02 jul. 2017.

ORTIGUEIRA. Lei n 137/2011. Plano de Empregos, Carreira e remuneração do Magistério Público Municipal de Ortigueira (PR). Câmara Municipal de Ortigueira: Ortigueira, 2011.

PALMEIRA. Lei $n^{\circ}$ 4133/2016. Plano de Empregos, Carreira e remuneração do Magistério Público Municipal de Palmeira (PR). Câmara Municipal de Palmeira: Palmeira, 2016.

PALMEIRA. Prefeitura Municipal de Palmeira. Concurso Público n 001/2017. Edital $n^{\circ} 001 / 2017$.

PARANÁ PORTAL NOTICIAS. 93 municípios do Paraná não seguem o piso salarial nacional para os professores. Disponível em: https://paranaportal.uol.com.br/cidades/93-municipios-do-parana-nao-seguem-opiso-salarial-nacional-para-os-professores/. Acesso em: 12 jun. 2017.

PAULA FREITAS. Lei $n^{\circ} 1335 / 2014$. Dispõe sobre a carreira, quadro de vagas e a remuneração do quadro do magistério. Câmara Municipal de Paula Freitas: Paula Freitas, 2014.

PAULA FREITAS. Lei n 790/2005. Plano de Empregos, Carreira e remuneração do Magistério Público Municipal de Paula Freitas (PR). Câmara Municipal de Paula Freitas: Paula Freitas, 2005.

PAULA FREITAS. Lei n 917/2007. Estabelece o Plano de Carreira, Empregos e Salários dos profissionais integrantes do Quadro da Educação Infantil e contém outras providências. Câmara Municipal de Paula Freitas: Paula Freitas, 2007.

PAULA FREITAS. Prefeitura Municipal de Paula Freitas. Concurso Público $\mathbf{n}^{\circ}$ 001/2015. Edital $n^{\circ} 001 / 2015$. 


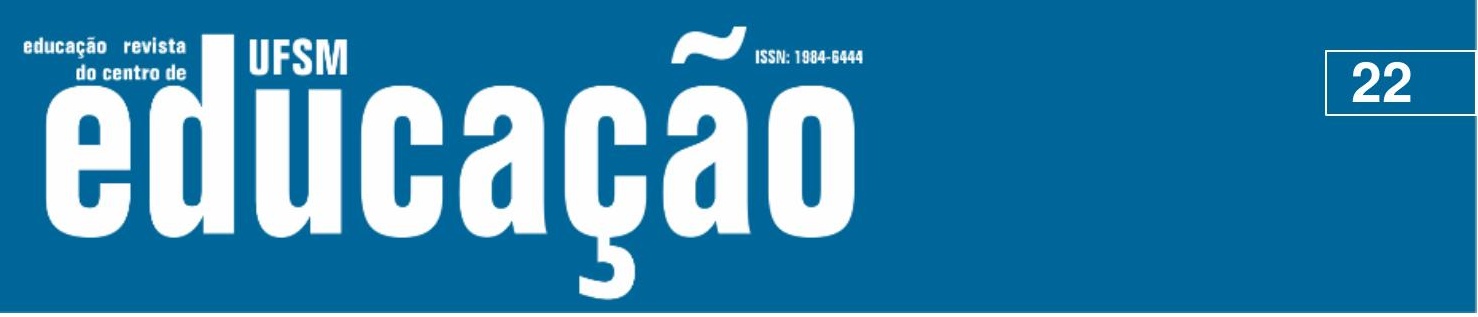

ISSN: 1984-6444 | http://dx.doi.org/10.5902/1984644438298

PAULO FRONTIN. Lei $n^{\circ}$ 366/2009. Plano de Empregos, Carreira e remuneração do Magistério Público Municipal de Paulo Frontin (PR). Câmara Municipal de Paulo Frontin: Paulo Frontin, 2009.

PAULO FRONTIN. Prefeitura Municipal de Paulo Frontin. Concurso Público $\mathbf{n}^{\circ}$ 001/2015. Edital $n^{\circ} 001 / 2015$.

PIRAÍ DO SUL. Lei n 1830/2011. Plano de Empregos, Carreira e remuneração do Magistério Público Municipal de Piraí do Sul (PR). Câmara Municipal de Piraí do Sul: Piraí do Sul, 2011.

PONTA GROSSA. Lei $n^{\circ}$ 12.269/2015. Plano de Empregos, Carreira e remuneração do Magistério Público Municipal de Ponta Grossa (PR). Câmara Municipal de Ponta Grossa: Ponta Grossa, 2015.

PONTA GROSSA. Prefeitura Municipal de Ponta Grossa. Teste Seletivo para provimento de vagas temporárias na Prefeitura Municipal de União da Vitória. Edital 002/2016.

PORTO VITÓRIA. Lei n 675/2003. Plano de Empregos, Carreira e remuneração do Magistério Público Municipal de Porto Vitória (PR). Câmara Municipal de Porto Vitória: Porto Vitória, 2003.

PORTO VITÓRIA. Prefeitura Municipal de Porto Vitória. Teste Seletivo para provimento de vagas temporárias na Prefeitura Municipal de Porto Vitória Paraná. Edital ${ }^{\circ} 001 / 2016$.

PRUDENTÓPOLIS. Lei n 1829/2011. Plano de Empregos, Carreira e remuneração do Magistério Público Municipal de Prudentópolis (PR). Câmara Municipal de Prudentópolis: Prudentópolis, 2011.

PRUDENTÓPOLIS. Prefeitura Municipal de Prudentópolis. Concurso Público $\mathbf{n}^{\circ}$ 001/2014. Edital $n^{\circ} 001 / 2014$.

REBOUÇAS. Lei n 1191/2008. Plano de Empregos, Carreira e remuneração do Magistério Público Municipal de Rebouças (PR). Câmara Municipal de Rebouças: Rebouças, 2008.

REBOUÇAS. Lei $n^{\circ}$ 1902/2015. Dispõe sobre adequações no plano de cargos, carreira e remuneração do magistério público municipal de Rebouças, e dá outras providências. Câmara Municipal de Rebouças: Rebouças, 2015.

REBOUÇAS. Prefeitura Municipal de Rebouças. Concurso Público n 001/2012. Edital $n^{\circ} 001 / 2012$.

RESERVA. Lei n 591/2014. Plano de Empregos, Carreira e remuneração do Magistério Público Municipal de Reserva (PR). Câmara Municipal de Reserva: Reserva, 2014. 


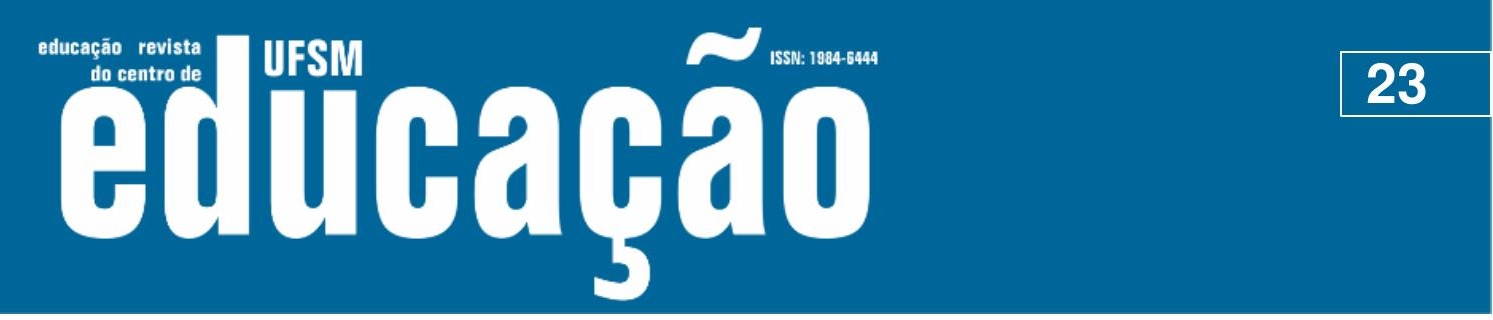

ISSN: 1984-6444 | http://dx.doi.org/10.5902/1984644438298

RESERVA. Prefeitura Municipal de Reserva. Concurso Público n 001/2016. Edital $n^{\circ} 001 / 2016$.

RIO AZUL. Lei $n^{\circ}$ 756/2014. Plano de Empregos, Carreira e remuneração do Magistério Público Municipal de Rebouças (PR). Câmara Municipal de Rebouças: Rebouças, 2008.

SÃO JOÃO DO TRIUNFO. Lei no 860/2003. Plano de Empregos, Carreira e remuneração do Magistério Público Municipal de São João do Triunfo (PR). Câmara Municipal de São João do Triunfo: São João do Triunfo, 2003.

SÃO JOÃO DO TRIUNFO. Prefeitura Municipal de São João do Triunfo. Concurso Público n001/2014. Edital n001/2014.

SÃO MATEUS DO SUL. Lei no 2000/2010. Plano de Empregos, Carreira e remuneração do Magistério Público Municipal de São Mateus do Sul (PR). Câmara Municipal de São Mateus do Sul: São Mateus do Sul, 2010.

SÃO MATEUS DO SUL. Prefeitura Municipal de São Mateus do Sul. Concurso Público n001/2012. Edital $n^{\circ}$ 001/2012.

TEIXEIRA SOARES. Lei no 1.709 de 27/11/2015. Dispõe sobre o Plano de Cargos, Carreira e Remuneração do quadro permanente do Magistério Público Municipal de Teixeira Soares. Prefeitura Municipal de Teixeira Soares. PR, 2015.

TEIXEIRA SOARES. Prefeitura Municipal de Teixeira Soares. Concurso Público $\mathbf{n}^{\circ}$ 001/2014. Edital $n^{\circ} 001 / 2014$.

TELÊMACO BORBA. Lei $n^{\circ}$ 1866/2012. Plano de Empregos, Carreira e remuneração do Magistério Público Municipal de Telêmaco Borba (PR). Câmara Municipal de Telêmaco Borba: Telêmaco Borba, 2014.

TELÊMACO BORBA. Prefeitura Municipal de Telêmaco Borba. Concurso Público $\mathbf{n}^{\circ}$ 001/2015. Edital $n^{\circ} 001 / 2015$.

TIBAGI. Lei $\mathrm{n}^{\circ}$ 2574/2015. Plano de Empregos, Carreira e remuneração do Magistério Público Municipal de Tibagi (PR). Câmara Municipal de Tibagi: Tibagi, 2015.

UNIÃO DA VITÓRIA. Lei no 3332/2005. Plano de Empregos, Carreira e remuneração do Magistério Público Municipal de União da Vitória (PR). Câmara Municipal de São União da Vitória: União da Vitória, 2005.

UNIÃO DA VITÓRIA. Lei no 3621/2008. Dispõe sobre implantação do novo plano de cargos, carreira e remuneração do magistério público municipal e dá outras providências. Câmara Municipal de União da Vitória: União da Vitória, 2008. 


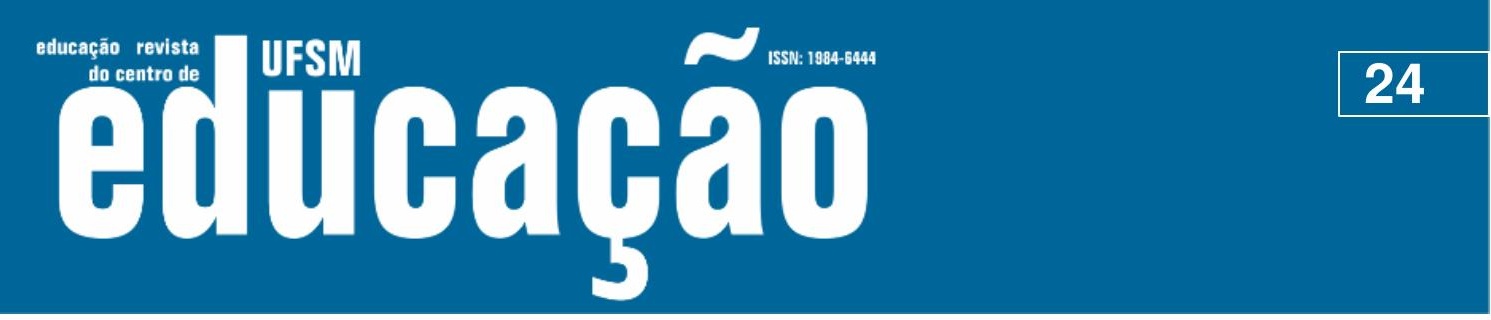

ISSN: 1984-6444 | http://dx.doi.org/10.5902/1984644438298

UNIÃO DA VITÓRIA. Prefeitura Municipal de União da Vitória Teste Seletivo para provimento de vagas temporárias na Prefeitura Municipal de União da Vitória. Edital $n^{\circ}$ 001/2014.

VAZ, Marta Rosani Taras; MASSON, Gisele. A (des) valorização profissional docente: implicações da oferta e demanda de pedagogos no Paraná (2009-2013). Práxis Educativa, Ponta Grossa, v. 12, n. 1, p. 223-243, jan./abr. 2017 Disponível em: http://www.revistas2.uepg.br/index.php/praxiseducativa/article/view/9503/0. Acesso em: 2 maio 2017.

VENTANIA. Lei $n^{\circ}$ 709/2016. Plano de Empregos, Carreira e remuneração do Magistério Público Municipal de Ventania (PR). Câmara Municipal de Ventania: Ventania, 2016.

\section{Correspondência}

Michelle Fernandes Lima - Universidade Estadual do Centro Oeste - Campus Irati, Rua Professora Maria Roza Zanon de Almeida Engenheiro - Gutierrez, CEP 84505-677. Irati, Paraná, Brasil.

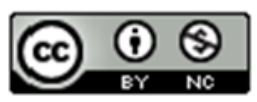

This work is licensed under a Creative Commons Attribution-NonCommercial 4.0 International (CC BY-NC 4.0)

\section{Notas}

\footnotetext{
${ }^{1}$ Agradecimentos à Capes, pelo financiamento.

2 Antônio Olinto; Bituruna; Cruz Machado; Fernandes Pinheiro; General Carneiro; Guamiranga; Imbituva; Ipiranga; Irati; Ivaí; Mallet; Paula Freitas; Paulo Frontin; Porto Vitória; Prudentópolis; Rebouças; Rio Azul; São João do Triunfo; São Mateus do Sul; Teixeira Soares e União da Vitória. Região Centro-Oriental: Arapoti; Carambeí; Castro; Imbaú; Jaguariaíva; Ortigueira; Palmeira; Piraí do Sul; Ponta Grossa; Reserva; Sengés; Telêmaco Borba; Tibagi; Ventania.

${ }^{3}$ Em Ponta Grossa, o avanço horizontal, segundo art. 90 do Plano de Carreira, observará o interstício de 2 anos, podendo avançar até duas referências mediante critérios mínimos de avaliação de desempenho. A cada interstício de 02 (dois) anos ficam computados até 40 (quarenta) pontos para atividades de formação e/ou qualificação profissional para cada referência. A cada 40 (quarenta) pontos acumulados, na forma do artigo anterior, o professor terá garantida a progressão equivalente a 01 (uma) referência, podendo avançar até 02 (duas) referências na carreira, por interstício de 02 (dois) anos.
}

${ }^{4}$ No caso de Sengés, tivemos acesso somente à tabela salarial, mas não à lei que estabelece o plano de carreira. 